\title{
Retaining Talent At LAAL: A Case Study
}

Robert C. Preziosi, (E-mail: Preziosi@ huizenga.nova.edu), Nova Southeastern University

\begin{abstract}
This case study is done in the approach used by the Harvard Business Review. It is fictitious to be used as a learning activity in a management, HRM or OB course. It has been used successfully in academic and corporate settings. Teaching notes are available from the author.
\end{abstract}

\section{INTRODUCTION}

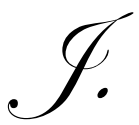

Cruz was sitting at his desk waiting for a telephone call from his company's Human Resources representative. The purpose of the telephone call was to conduct an exit interview over the telephone. Cruz had decided to leave his employer of eight years, Latin American Air Lines (LAAL).

Cruz had started out as a Customer Service Representative for LAAL in 1990. He had an excellent work record. During his first twelve months as a Customer Service Representative, he had accumulated fifteen letters in his personnel file from customers that were very impressed with his customer service skills. He was promoted to Senior Service Representative a month later after his first year performance evaluation.

The Vice President of Customer Service began to take notice. Cruz was identified as an individual that the organization needed to retain. "This is the kind of employee that will help the company grow at faster rates," said the Vice President.

\section{LAAL}

LAAL had been a small regional carrier covering most countries in Central America. Through a series of acquisitions it had become one of the largest carriers in Central and South America. The path for continued growth in the region was clear. LAAL had decided to position itself as the premium carrier in the region. This would require a high-performance workforce dedicated to being the best in the business.

Cruz was well aware of this within a month after he had started his employment. He understood that being the best was not just a slogan, it was one of the company's core values. The others were: focus on the customer, emphasize the people requirements, and do the right thing. These values served as the foundation for developing one standard of service. Customers throughout the region should expect that the people and processes in all the countries would be consistent enough to deliver the "premium product."

Cruz really valued his first boss at LAAL, C. Llorens. Llorens had grown up in Brazil and possessed a great deal of cultural sensitivity and awareness. She thought that it was very important to understand all the cultures of employees and customers. There were many multi-cultural issues that could best be addressed when a person understood the various cultures. The issues could be as simple as communicating a new policy across cultures to something as difficult as developing poly-cultural service teams. Llorens worked tirelessly at developing such teams because of the value-added impact that this had on the growing business. Poly-cultural service teams added value because they always led to employees looking at things from different perspectives. This led to "right" answers. 


\section{CORPORATE IMPROVEMENT INITIATIVES}

Within a few months, Cruz was tapped to become a Customer Service Supervisor. Cruz's new boss found a supervisory skills workshop for the new supervisor to attend. This was an important training program for Cruz because the young LAAL supervisor had never been a supervisor before and had never received any training in how to be a successful supervisor in a high-performance corporate culture. LAAL was definitely building a higherperformance culture and was counting on its supervisors and managers to help shape the high-performance culture. Human Resources could not build the new culture alone. The HR exec had told Cruz, "you are the future at LAAL". "Keep up the excellent work".

Building a high-performance culture was not the only initiative underway at LAAL. M. Bergamo, the regional head of Human Resources was spearheading an effort to increase communication throughout the region. The principal aim of this project was to get wider and deeper information exchange among all levels of employees. The senior management team was the driving force for this. The need for this had been identified in the annual Employee Opinion Survey (EOS). Informal feedback had led Bergamo to believe that this initiative was going well. Cruz was thrilled that it was going well because it was consistent with what Cruz had seen so far in the Customer Service Department.

Bergamo was also building a four-level leadership development program. Corporate had approved special project funding for this based upon the projection of a 15-percent growth rate in the business over the next five years. Cruz's boss was a member of the task force that was working with Bergamo in an advisory capacity. Cruz's boss used to return from the meetings boasting about being on the task force. However, when Cruz asked questions about the task force, the boss had nothing to say. Cruz thought that this was inconsistent with the initiative aimed at opening up communication. The boss told Cruz that the information would become available when the time was right.

\section{THE ROLE OF HUMAN RESOURCES}

Cruz was surprised by Llorens' response. It had become clear to Cruz that the Human Resources Department was a strategic ally for all line and staff managers and executives who were charged with "raising the bar" on performance requirements.

Managers had to learn how to better deal with the changing markets and more aggressive competition. Also, the company had become so large that it was more centralized and less entrepreneurial. Cruz had said to his boss, "we are losing our competitive advantage".

Communication needed not only to be wider and deeper, but it also needed to be more formal and less informal. People throughout the region would continue their informal, social discussions. Business communications, though, needed to be more formal to prevent misunderstandings and to ensure that all communications arrived at the right time, in the right format, to the right person(s). This meant always asking the right questions and encouraging debate until the right answer was found. Everyone knew that getting people to debate would be a difficult task. It was counter to most cultures.

Bergamo was the right person to lead strategic Human Resources activities. He knew that Human Resources could help drive profits up by getting LAAL to invest more in human capital. He knew that culture change and training would lead to maximizing the recruitment and retention of high performers. He knew how to work toward LAAL's business objectives by getting the whole company involved in high-value Human Resources efforts. It was the task of everyone, not just Human Resources, to create a high-performance culture in LAAL.

\section{THE PROMOTION}

Cruz continued to be a significant contributor. He was not perfect, but he continued to stand out in the crowd. He believed deeply in what he was doing and in the company. He was determined to have an impact. Some people that he was a little peculiar, and he made some people mad. Cruz's boss always came to his defense because 
the boss recognized that Cruz was a peak performer. Cruz exemplified what the culture was becoming. He always wanted to know how his job was impacting the bottom line.

Cruz was promoted to Senior Supervisor in the Customer Service Department. By then, Cruz had been with LAAL for a little less than three years. He was averaging one promotion per year. People were so happy about his most recent promotion that they threw a party for him after work one Thursday evening. He had a little too much to drink and raised some eyebrows with his resulting behavior. The next day Cruz's boss reminded him that senior supervisors had a higher responsibility to the company. They discussed the behavior of the night before. Cruz apologized to people that were offended by the Thursday evening behavior. Cruz vowed to keep in mind that an employee is always a representative of the company, even when not on company premises or conducting company business. Cruz said to his bos, "thank you for re-directing my sensitivity of role".

It was the tone of the discussion of Cruz's party behavior that struck him the most. The boss had not taken an authoritarian or aggressive approach with Cruz. The boss asked Cruz a few questions and listened carefully to Cruz's responses. They explored the behavior together. Cruz had really come to the conclusion himself that behavior change was necessary. The learning had come from within. This was the result, Cruz reminded himself, of the twoday coaching skills training that the boss had received. Cruz had been to the same training. It was for everyone who supervised others.

Bergamo was happy to hear from Cruz. He knew Cruz would be going far in the company. He was even more excited to hear about Cruz's assessment of the coaching situation with the boss. Bergamo had convinced senior management that coaching skills training was essential to building a high-performance culture. It sounded like the training was worth the investment.

\section{THE DAYDREAM}

These were some of Cruz's thoughts as he sat there waiting for the phone to ring. Surely the interview was not going to be a history lesson. However, Cruz did want the interviewer to know about the path he had taken at LAAL. At one time he had thought he might even be vice president material. He had never discussed his desire with anyone. Now it was a moot topic.

The phone rang. Cruz was startled. He answered the phone quickly. It was a friend who called to wish him well on his departure. The call kept Cruz on the phone for a few minutes. His mind wandered a bit. He recalled how everyone had favorably responded to Human Resources' new web site. It was an example of how technology can be used to impact Human Resources' contribution to the business. It gave people electronic access to personnel information and had cut annual printing costs by $\$ 500,000$.

After hanging up the phone, Cruz's thoughts returned to what he had been thinking about prior to the call. Cruz remembered what a terrific job he had been promoted in to. As a Senior Customer Service Supervisor, he had a good deal of autonomy and variety in his work. Cruz was given the opportunity to work on special projects that gave him a broader understanding of the business. He developed excellent problem-solving skills. His subordinates appreciated his participative approach to supervising. They also admired his quick decision making when they needed an "on the spot" answer.

One of the areas that interested Cruz a great deal was business process improvement. It was not a prime focus at LAAL, but there was always discussion about how fast Southwest Airlines employees can clean and prepare an arriving aircraft for departure. Indeed, there was so much discussion, that no one was surprised that at the beginning of Cruz's fifth year with the company business process improvement was set forth by the corporate senior management team as the top priority for the coming year. Business process improvement was now viewed as a competitive advantage. He had once been told that improving processes could make or break the company. 
Cruz could not contain his excitement. A friend who worked in the manufacturing business gave him a copy of Business Process Assessment Tool (BPAT). It had been developed by a university professor to assess business processes from four different perspectives:

$\begin{array}{ll}\text { - } & \text { Organization Leadership and Policy } \\ \text { - } & \text { Eustomer Needs } \\ \text { - } & \text { Supployee Practices } \\ & \text { Suprective }\end{array}$

Cruz diligently used the BPAT as a guide to collect data in the Customer Service Department. He analyzed the data and shared the results with his boss. They discussed different options for improving business processes in the department. Cruz got many employees involved in this endeavor. By the end of the third quarter, Cruz was able to present some quantifiable results and assign dollar values. The senior management team in the region began to take notice of Cruz's project. Near the end of the year, a couple of business process improvement teams that Cruz had formed were honored at a regional managers meeting by the Corporate Vice President of Operations. The Vice President announced that the focus on business process improvement would continue for another year.

\section{VAYA CON DIOS}

A month after the ceremony, Cruz was asked to come to a meeting in his boss's office. The boss had received a conference call from the Country Manager of Chile and the Regional Director of Operations. They had called to ask if Cruz would be interested in going to Chile as Operations Manager. Cruz told his boss that he was honored to be considered for such a position. He asked for two days to think about the possibility of moving to Chile.

Cruz thought the job was a good opportunity. There were some minor drawbacks to it, though. He had spent his entire life in Bogota. All of his family and friends still lived in Bogota. He had all matters working smoothly in his Customer Service area. He had been hoping for another promotion in his hometown. However, Cruz did not think that another promotion in Bogota would be available any time soon.

Cruz decided to accept the promotion to Operations Manager of Chile. He went in to tell his boss. The two of them called the country manager of Chile, B. Heinholt. During the conference call, the three of them were trying to decide the day that Cruz would report to work in Chile. It was difficult to reach agreement. Heinholt was eager to have Cruz in Chile as soon as possible. Cruz wanted three weeks because he had a lot of personnel arrangements to make. Cruz's boss favored four weeks because he wanted to ensure a smooth transition. Colombia was the second largest market in the region and the boss did not want any negative effect on the Customer Service function. The discussion ended with Heinholt's perspective winning out. Cruz was to start his new job in two weeks. He knew that things would be hectic during the two-week period, but he was looking forward to the opportunity.

During the two-week period, Cruz managed to get things ready for a smooth transition in Bogota. He had promised his boss that he would be as much help as necessary from Chile. The pace and amount of emails from Heinholt increased as the two weeks went by. Cruz felt as if he was in Chile already. However, he did find time to enjoy his going-away party. Practically everyone in the Bogota office came by to wish Cruz well. Though he had only worked directly with a small percentage of the office employees, everyone had heard about him and appreciated his hard work that had a significant impact on the business.

\section{HOLA, CHILE!}

It was not just the increasing pace and amount of emails from Chile that Cruz noticed. It was also the fact that they only came from Heinholt and that they became more directive and less friendly. Cruz thought that all of that was because Heinholt had been without an Operations Manager for almost two months. Even though Chile was a smaller market than Colombia, it was a busy port of call for the Operations Manager. Above all, though, Cruz was eagerly looking forward to starting on the job. He saw it as a way to make a greater contribution to the success LAAL. 
When Cruz arrived at his new work site in Chile, he was a little surprised. People were polite but not very friendly. As Cruz surveyed the sea of faces, he saw few smiles.

Heinholt was ready for Cruz to get to work. Cruz was fully aware of what the job entailed. Heinholt had been pretty clear about the problems that existed in Chile. Everything seemed to be running a little bit behind schedule. Supplies seemed to run out before the next ordering cycle. Everyone seemed to be operating at a low energy level. One employee said to Cruz, "it's no longer fun to work here".

Something that Cruz was not aware of when he arrived in Chile was the high level of turnover across all job functions. He was well aware that building a high-performance culture meant that some people would leave LAAL. He though the overall turnover rate of 22 percent was a bit high. Both Heinholt and the Country Human Resources Manager for Chile, F. Montenegro, told Cruz that it was the nature of the business that created turnover. Also, Chile was a country of transients. Cruz was not so sure of these explanations.

\section{THE EMPLOYEE OPINION SURVEY (EOS)}

About the time Cruz arrived for his new job in Chile, the results of the annual EOS were delivered to all country managers. Each country manager was then to share the results with their management team and, as appropriate, the rest of the work force. Projects would be implemented when areas for improvement were clearly identified.

Cruz was aware that Heinholt had not been open about the results of the survey. The fact that Heinholt did not involve others in the Chile office in analyzing and acting on the EOS results did not seem to matter much to the regional senior managers. After all, Chile was such a small market. Its contribution to profit was minimal, but it was necessary for LAAL to be present in the Chilean market. Still, given the corporate communications initiative, Cruz was certain that Heinholt would engage all the employees in an open dialogue about the results of the EOS. Also, such action would be consistent with the corporate values.

Cruz was very surprised when he was told at his regular Monday afternoon meeting with Heinholt that the country manager usually handled the EOS results alone. Cruz was also disappointed. At his previous work site, Cruz had always enjoyed the open communication and improvement projects connected with the EOS. It was one of the things that kept him excited about working at LAAL. Regardless of his job title, and responsibilities, Cruz had always been a value-adding force to the EOS process. Now here he was a part of the country management team and he was not going to be a part of the EOS communications process. Surely Bergamo must have known about this. He decided to call Bergamo. Cruz was interrupted and forgot to call Bergamo.

Turnover was slowed down a bit after Cruz arrived. Cruz was a more reinforcing and rewarding manager than his predecessor had been. He had learned the value of such behavior not just in his training classes, but also in his hands-on experience as a Supervisor in Colombia. He felt that he was on the right track in Chile. Employees seemed more positive in their attitude as compared to when he first arrived, Cruz noted to himself. Despite the success that he was feeling, Cruz still wondered when something would surface around the EOS results. Cruz telephoned his mentor an said, "I need guidance".

Cruz, the new Operations Manager, decided that the lack of activity surrounding the EOS was not good for employee relations or business. He knew that good employee relations equals good customer relations. He knew that, over time, employees treat customers the same way that they are treated. Certainly the EOS scores were not perfect and there was some room for improvement in employee relations in the Chile office. He felt that it was very important that he approach Heinholt again about the EOS. Before doing this, Cruz spoke to his mentor who was now working in Mexico. The conversation was brief. The mentor congratulated Cruz on his courage to follow up with Heinholt on the EOS. He went on to remind Cruz that the EOS was an initiative of Human Resources with the full support of the senior management team. Perhaps Cruz should talk to Human Resources in their role as strategy ally, his mentor suggested. Cruz decided against taking that suggested action. 


\section{THE EOS SHOWDOWN}

Cruz and Heinholt not only sat across from each other at the conference table, they also were on opposite sides of the EOS issue. Heinholt viewed the EOS as an intrusion. He said he did not need anyone giving him feedback about how to run the business. He thought that as the country manager, he was the only person being held responsible for the success of the business. Cruz tried to get Heinholt to access the EOS as a management tool that could be used to develop people and, thus, help grow the business. Heinholt countered that he knew how to run the business.

In a final attempt to change Heinholt's opinion, Cruz talked about the significant investment in time and money that the company had made in the EOS. This investment seemed to Cruz as a strong indication that the company's senior management team expected country managers to use the results. Heinholt did change his perspective a little as he agreed to let Cruz see the data generated by the EOS for Chile. "However," said Heinholt, "you are not to discuss anything you read in the report with anyone."

Cruz was not impressed with what the EOS results for Chile. The scores he had seen in Colombia had always been much better. He surmised that Heinholt did not want to do anything because of embarrassment over the poor scores. However, Cruz had no real facts to back up that opinion. His other thought was that Heinholt felt it was all right to hide bad news. The low scores were certainly bad news. Again, though, Cruz had no facts.

The most disturbing aspect of the EOS data that Cruz was reviewing was the huge discrepancy in the emphasis on business results vs. emphasis on people. The scores indicated that the employees in Chile felt as if the emphasis on achieving business results was almost twice as important as the emphasis on people. Cruz knew from previous experience that a balance between the two was more desirable.

Cruz called Heinholt's boss to explain what he thought was a horrible situation that needed to be fixed. The executive was sympathetic to what Cruz had to say and agreed to call Heinholt to discuss the issue with him. The executive called Heinholt as promised. Cruz found out about this because Heinholt reprimanded him for going over his head. Heinholt told Cruz that if anything like that happened again, Cruz would need to find another job. He reminded Cruz that there were too many people from too many different cultures for the EOS data to be meaningful.

Cruz felt defeated and beaten down. He called his mentor for advice. The response he received was what he expected. "You have done everything you could do about the EOS," said the mentor. He went on to say that Cruz should re-focus his attention on other work priorities. "Your main goal is to select and retain employees and help them do their best work," advised the mentor.

Cruz reminded himself how important it as to continue his efforts of rewarding and reinforcing employees for good performance. He also would emphasize process improvement projects. His level of energy, though, was not the same. Some days he felt as if he was just going through the motions. He wasn't emotionally charged like he was in Colombia and during his first few months in Chile. Adding to his negative mood was the fact that Heinholt had become distant in his relationship with Cruz. They only spoke to each other when they had to. There were no friendly exchanges and no shared smiles.

\section{THE TURNING POINT}

About a year had passed since Cruz arrived in Chile. He and Heinholt had a heated argument in Heinholt's office on August 10. The next day Heinholt criticized Cruz in front of a half-dozen employees. Cruz's spirit declined even further. He called his mentor who was able to inject some spirit into the dejected Cruz. It was only a temporary solution. The next week Cruz's request to upgrade some old technology was rejected by Heinholt saying that it would have a negative impact on the bottom line. 


\section{THE EXIT INTERVIEW}

The telephone rang. It was the Regional Human Resources Representative. It was time for Cruz's exit interview. He answered each question openly and honestly. The final question was the most difficult. Cruz was asked to give the number one reason why he was leaving LAAL. He wanted to recount everything that he had been thinking about while waiting for the phone call. However, he kept his answer brief. He said that he had loved working for LAAL, but it had become clear to him during his last year with the company that they really did not care about people and that the only important priority to the company seemed to be money. He was looking forward to a more caring situation as General Manager of the Corona plant in Puerto Vallarta.

\section{NOTES}


NOTES 